\title{
Rubrofusarin Attenuates Chronic Restraint Stress-Induced Depressive Symptoms
}

\author{
Jee Hyun Yi ${ }^{1,+}$, Jieun Jeon ${ }^{2,+}{ }^{,}$Huiyoung Kwon ${ }^{2,+}{ }^{+}$Eunbi Cho ${ }^{2}$, Jeanho Yun ${ }^{3}{ }^{\circ}$, \\ Young Choon Lee ${ }^{2}$, Jong Hoon Ryu ${ }^{4}$, Se Jin Park ${ }^{5}$, Jong Hyun Cho ${ }^{2, *}$ and Dong Hyun Kim ${ }^{2, *}$ \\ 1 Center for Synaptic Brain Dysfunctions, Institute for Basic Science, Daejeon 169148, Korea; \\ jeehyunyi@kaist.ac.kr \\ 2 Department of Medicinal Biotechnology, College of Health Sciences, Dong-A University, Busan 49315, Korea; \\ ji6785@naver.com (J.J.); kwonhuiyoung@naver.com (H.K.); bee2634@naver.com (E.C.); \\ yclee@dau.ac.kr (Y.C.L.) \\ 3 Department of Biochemistry, College of Medicine, Dong-A University, Busan 49201, Korea; yunj@dau.ac.kr \\ 4 Department of Oriental Pharmaceutical Science, College of Pharmacy, Kyung Hee University, Seoul 02447, \\ Korea; jhryu63@khu.ac.kr \\ 5 School of Natural Resources and Environmental Sciences, Kangwon National University, Chuncheon 24341, \\ Korea; sejinpark@kangwon.ac.kr \\ * Correspondence: jhcho1@dau.ac.kr (J.H.C.); mose79@dau.ac.kr (D.H.K.); \\ Tel.: +82-51-200-7562 (J.H.C.); +82-51-200-7583 (D.H.K.) \\ + These authors equally contributed to this study.
}

Received: 29 April 2020; Accepted: 11 May 2020; Published: 13 May 2020

check for updates

\begin{abstract}
The aim of this study was to examine whether rubrofusarin, an active ingredient of the Cassia species, has an antidepressive effect in chronic restraint stress (CRS) mouse model. Although acute treatment using rubrofusarin failed, chronic treatment using rubrofusarin ameliorated CRS-induced depressive symptoms. Rubrofusarin treatment significantly reduced the number of Fluoro-Jade B-positive cells and caspase-3 activation within the hippocampus of CRS-treated mice. Moreover, rubrofusarin treatment significantly increased the number of newborn neurons in the hippocampus of CRS-treated mice. CRS induced activation of glycogen synthase kinase- $3 \beta$ and regulated development and DNA damage responses, and reductions in the extracellular-signal-regulated kinase pathway activity were also reversed by rubrofusarin treatment. Microglial activation and inflammasome markers, including nod-like receptor family pyrin domain containing 3 and adaptor protein apoptosis-associated speck-like protein containing CARD, which were induced by CRS, were ameliorated by rubrofusarin. Synaptic plasticity dysfunction within the hippocampus was also rescued by rubrofusarin treatment. Within in vitro experiments, rubrofusarin blocked corticosterone-induced long-term potentiation impairments. These were blocked by LY294002, which is an Akt inhibitor. Finally, we found that the antidepressant effects of rubrofusarin were blocked by an intracerebroventricular injection of LY294002. These results suggest that rubrofusarin ameliorated CRS-induced depressive symptoms through PI3K/Akt signaling.
\end{abstract}

Keywords: rubrofusarin; depressive disorder; chronic restraint stress; neuroinflammation; Akt; synaptic plasticity

\section{Introduction}

Exposure to stress is known to affect various brain functions [1,2]. For instance, acute stress induces norepinephrine and glucocorticoid release from the adrenal glands, causing bodily changes, allowing individuals to adaptively respond to the stressor [3-5]. However, the experience of chronic stress is believed to be involved in the onset of depression [6,7]. Constant feelings of low self-esteem 
and anhedonia are the main symptoms of depression. Different forms of stress can induce different depression conditions [8,9]. Although the exact mechanisms underlying the onset of depression are unknown, many drugs for patients with depression were developed based on the theory that levels of monoamine neurotransmitters are low in these patient's brains [10,11]. However, current antidepression drugs not only are not fully effective for patients but also possess severe side effects [12-14]. Thus, developing antidepressants is of importance.

Monoamine neurotransmitters, including serotonin, dopamine, and norepinephrine, are involved in various psychological aspects such as mood, emotion, arousal, and compensation. Insufficient levels of monoamine neurotransmitters are related to the pathophysiology underlying depression $[15,16]$. Most frequently prescribed antidepressants currently include Prozac (fluoxetine) and Zoloft (sertraline). These are selective serotonin reuptake inhibitors which were developed based on the monoamine theory, where other food and drug administration (FDA)-approved antidepressants are also based on the monoamine theory. However, these antidepressants have various side effects such as nausea, loss of sexual desire, and insomnia [17]. Moreover, studies revealed that antidepressants reduce depressive symptoms in $50 \%$ of patients and prevent relapses in $23 \%$ of patients [18]. Therefore, new antidepressants should be developed for better treatment efficacy.

Rubrofusarin, which is isolated from the Cassia species, is a member of the class of benzochromenones. Rubrofusarin has been reported to have anticancer, antibacterial, and antioxidant effects [19-21]. Recently, we found that rubrofusarin prevents amyloid- $\beta$ (A $\beta$ ) aggregation and improves Alzheimer's disease-like dementia [22]. Moreover, recent studies reported that rubrofusarin inhibits monoamine oxidase- $\mathrm{A}$, which can degrade norepinephrine, serotonin, and dopamine, with good blood-brain barrier penetration value [23]. These suggest that rubrofusarin may increase monoamine neurotransmitter levels in the brain and demonstrate antidepressant-like effects. Thus, this study aimed to test the effects of rubrofusarin on the onset of depressive symptoms in a chronic restraint stress-induced depression-like model and mode of action.

\section{Results}

\subsection{Chronic Rubrofusarin Administration Ameliorated Chronic Restraint Stress (CRS)-Induced Depressive Symptoms}

To examine the effect of rubrofusarin (RF, Figure 1A) on CRS-induced depressive symptoms, we administered rubrofusarin to mice $1 \mathrm{~h}$ before the restraint stress for 11 days. Mice experienced restraint stress for $4 \mathrm{~h}$ a day for 11 days (Figure 1B). To test the effect of rubrofusarin on CRS-induced cognitive dysfunction, an object recognition test was conducted. During a habituation session, the CRS-treated group showed significantly shorter exploration time in the center zone of the open field compared to control group. This suggested that CRS increased anxiety. RF ( $30 \mathrm{mg} / \mathrm{kg}$ ) or fluoxetine (FLX, $10 \mathrm{mg} / \mathrm{kg}$ )-treated CRS groups showed no significant changes in the time spent in the center zone compared to the control group (F4,45 $=5.619, p<0.05, n=10$ /group, Figure 1C), suggesting reductions in anxiety. During the training session, there were no significant differences in the total exploration time for the two objects between groups ( $F 4,45=0.475, p>0.05, n=10$ /group, Figure 1D). During the test session, the CRS group showed a significantly lower discrimination index compared to the control group, suggesting potential impairment in recognition memory. RF (30 mg/kg) or FLX $(10 \mathrm{mg} / \mathrm{kg}$ )-treated CRS groups showed significantly higher discrimination ratios compared to the CRS group (F4,45 $=5.648, p<0.05, n=10$ /group, Figure 1E). During the forced swimming test for testing levels of depression, the CRS group showed significantly higher immobility time compared to the control group. RF (30 mg/kg) or FLX (10 mg/kg)-treated CRS groups showed significant reductions in immobility time compared to the CRS group (F4,45 $=3.733, p<0.05, n=10$ /group, Figure 1F). These behavioral results suggest that RF reduced CRS-induced depressive symptoms including anxiety, memory impairments, and overall levels of depression. 
A<smiles>COc1cc(O)c2c(O)c3c(=O)cc(C)oc3cc2c1</smiles>

B Stress \& drugs

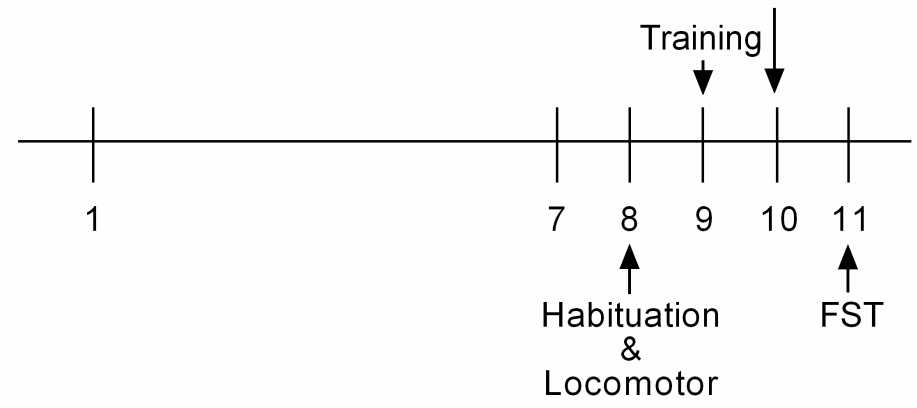

C

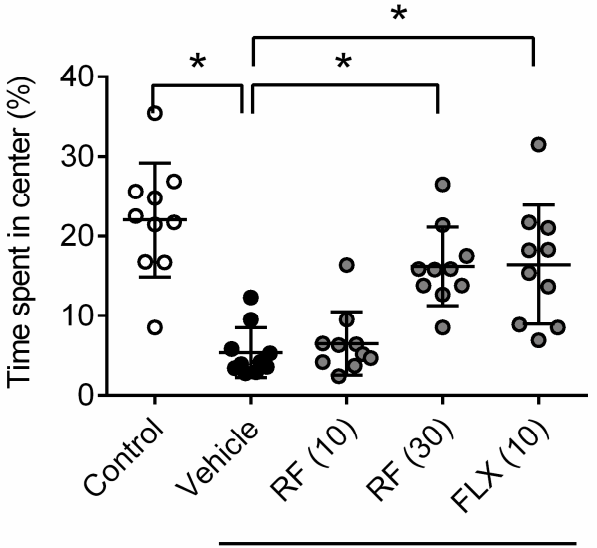

Restraint stress

$E$

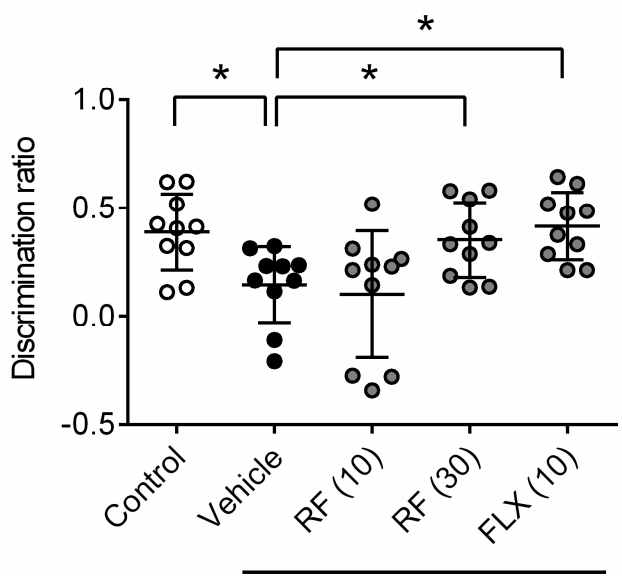

Restraint stress
D

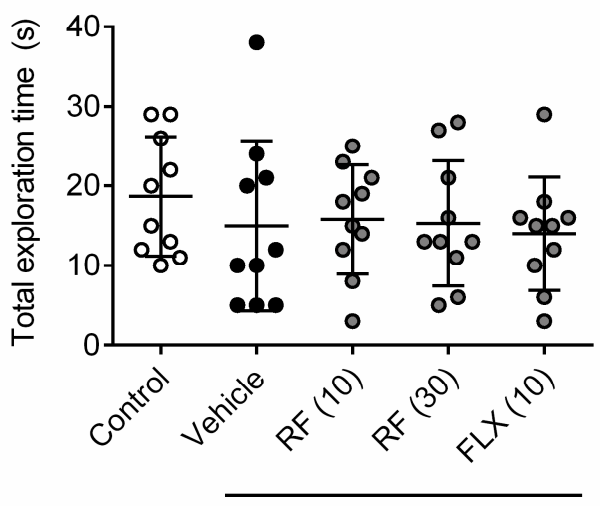

Restraint stress

F

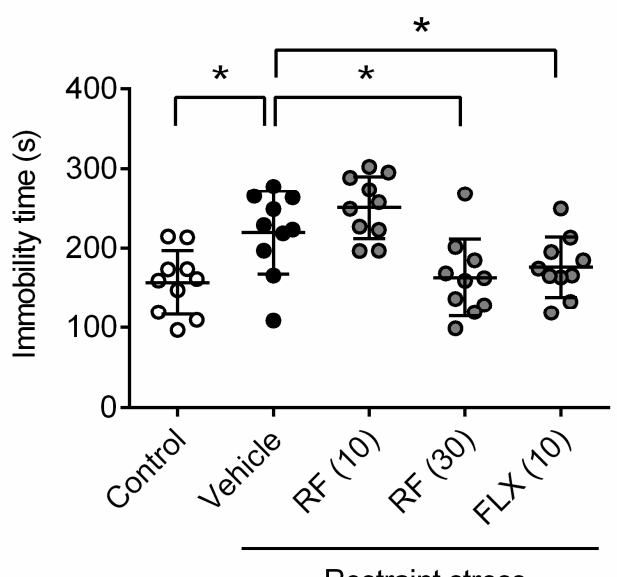

Figure 1. Effect of rubrofusarin on depressive symptoms: Restraint stress ( $4 \mathrm{~h}$ per day) was treated for 11 days. Rubrofusarin (10 or $30 \mathrm{mg} / \mathrm{kg}$ ) or fluoxetine $(10 \mathrm{mg} / \mathrm{kg}$ ) was administered to mice $1 \mathrm{~h}$ before the restraint stress treatment. (A) Structure of rubrofusarin. (B) Schematic diagram of experimental schedule. (C) Time spent in the center of an open field in the habituation trial of object recognition test. (D) Total exploration time for objects in training trial of object recognition test. (E) Discrimination ration in the test trial of an object recognition test. (F) Immobility time in forced swimming test. Data represented as mean $\pm \mathrm{SD}$ with raw data. ${ }^{*} p<0.05$. 


\subsection{Chronic Rubrofusarin Administration Rescued CRS-Induced Hippocampal Neuronal Damage}

Previous reports indicated that CRS causes neurodegeneration in the hippocampus [24]. To test whether RF rescues CRS-induced neuronal cell death, we conducted Fluoro Jade-B (FJB) staining (Figure 2A). Mice were sacrificed $1 \mathrm{~h}$ after the forced swimming test (FST) test for FJB staining. The CRS-treated group showed significantly more FJB-positive cells in the hippocampal dentate gyrus (DG) region $(p<0.05)$. RF $(30 \mathrm{mg} / \mathrm{kg})$ or FLX $(10 \mathrm{mg} / \mathrm{kg})$ treatment blocked the increase of FJB-positive cells by CRS (F4,20 $=41.01, p<0.05, n=5$ /group, Figure $2 \mathrm{~B}$ ). The FJB results suggest that RF blocked CRS-induced neuronal cell death in the hippocampus.

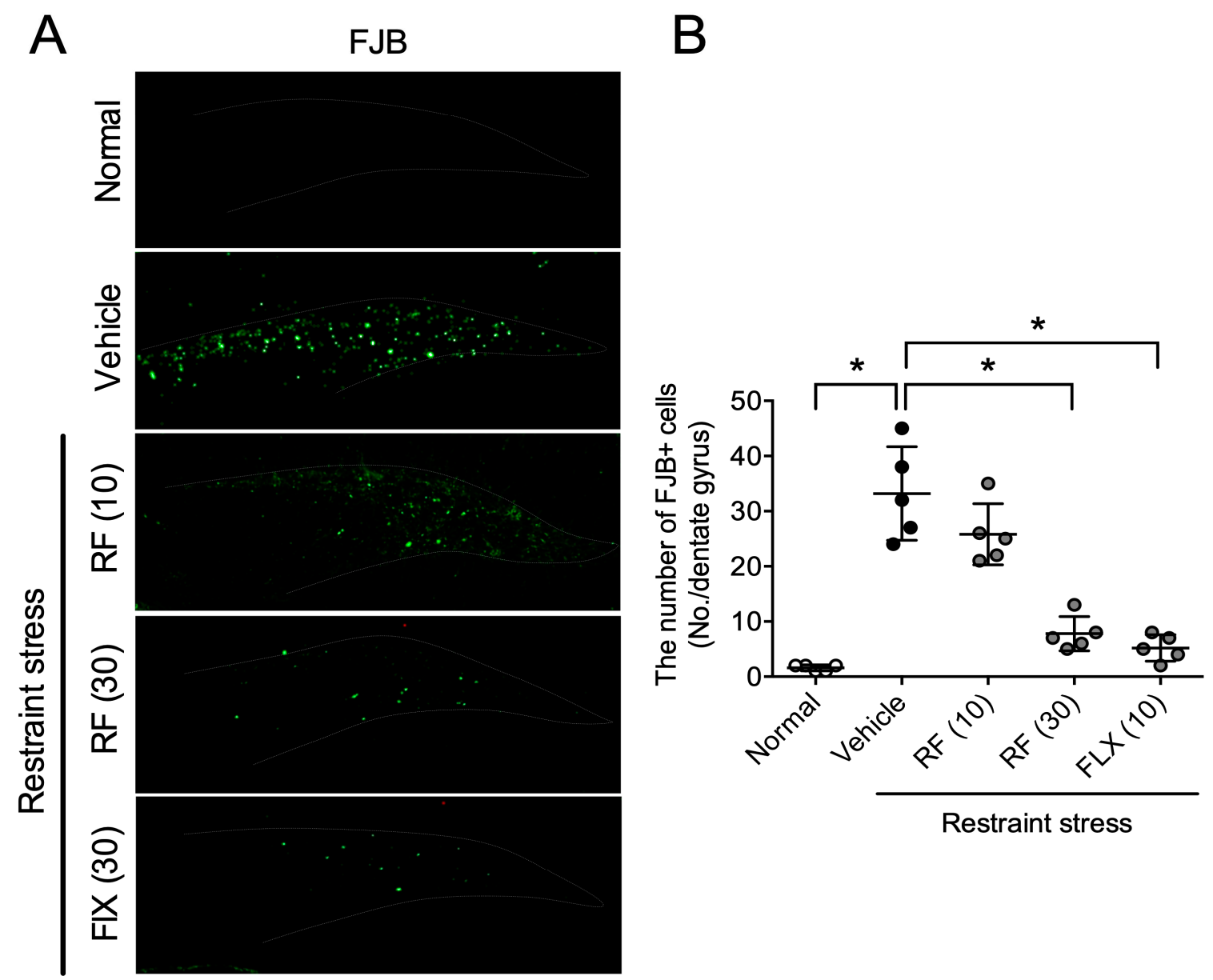

Figure 2. Effect of rubrofusarin on neurodegeneration: (A) Photomicroscopic image of Fluoro Jade-B (FJB)-positive cells in the dentate gyrus region. (B) Quantitative analysis of the number of FJB-positive cells in the dentate gyrus region. Data are represented as mean \pm SD with raw data. ${ }^{*} p<0.05$.

\subsection{Chronic Rubrofusarin Administration Blocked CRS-Induced Reduction of Adult Neurogenesis}

Various animal models and patients with major depressive disorders show reductions in adult neurogenesis within the hippocampus [25]. To test whether rubrofusarin ameliorates reductions in neurogenesis using the CRS model, we measured doublecortin-positive cells in the hippocampus. Mice were sacrificed $1 \mathrm{~h}$ after the FST test for doublecortin immunostaining. The CRS-treated group showed significant reductions in the number of doublecortin-positive cells in the DG region of the hippocampus $(p<0.05$, Figure $3 \mathrm{~A}, \mathrm{~B})$. RF treatment ameliorated this reduction in a dose-dependent manner (F4,20 $=9.615, p<0.05, n=5 /$ group, Figure 3B). FLX also ameliorated the reduction in the number of doublecortin-positive cells in CRS-treated mice $(p<0.05$, Figure $3 \mathrm{~A}, \mathrm{~B})$. 
A
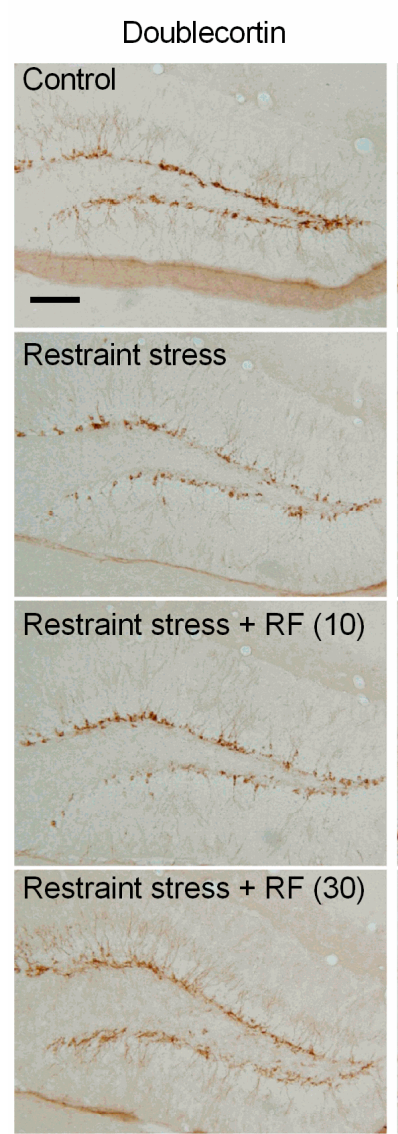

Restraint stress + FLX

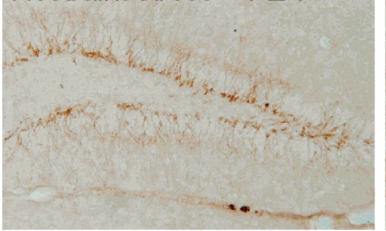

Figure 3. Effect of rubrofusarin on adult neurogenesis:

(A) Photomicroscopic image of doublecortin-positive cells in the dentate gyrus region. Bar $=100 \mu \mathrm{m}$. (B) Quantitative analysis of the number of doublecortin-positive cells in the dentate gyrus region. Data represented as mean $\pm \mathrm{SD}$ with raw data. ${ }^{*} p<0.05$.

\subsection{Chronic Rubrofusarin Administration Blocked CRS-Induced Neuroinflammation}

Inflammation within the CNS is a component of depression [26,27]. Therefore, we observed the effect of RF on CRS-induced neuroinflammation. It was found that CRS induced microglial activation in the hippocampus (Figure 4A,B). RF (30 mg/kg) and FLX (10 mg/kg) significantly suppressed CRS-induced microglial activation (F4,15 $=6.367, p<0.05, n=4$ /group, Figure 4B). The immunohistochemical result suggests that RF blocked CRS-induced neuroinflammation.

\subsection{Chronic Rubrofusarin Administration Blocked CRS-Induced Synaptic Dysfunctions}

Synaptic dysfunctions in the brain of patients with depression were reported [28]. Therefore, we tested the effect of RF on synaptic dysfunction in the CRS-treated depression model. Long-term potentiation (LTP) was significantly reduced in the hippocampus of the CRS-treated group $(p<0.05$, Figure 5A). This reduction was ameliorated by RF (Figure 5B,C) or FLX (Figure 5D) treatment $(p<0.05$ ). These results suggest that RF blocked CRS-induced synaptic deficits. 
A
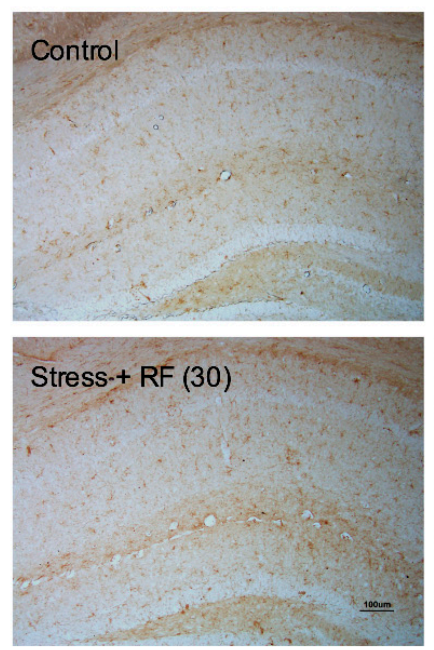
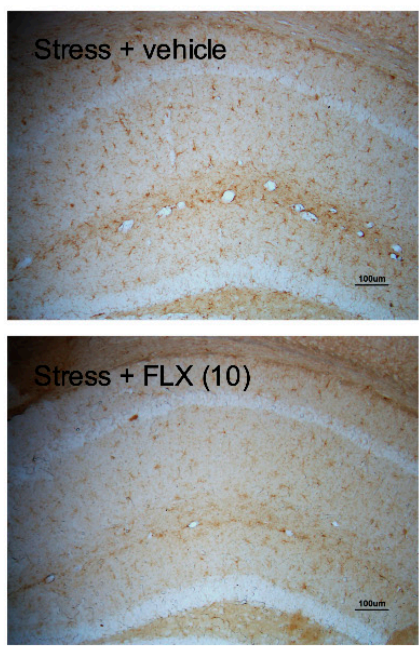

B

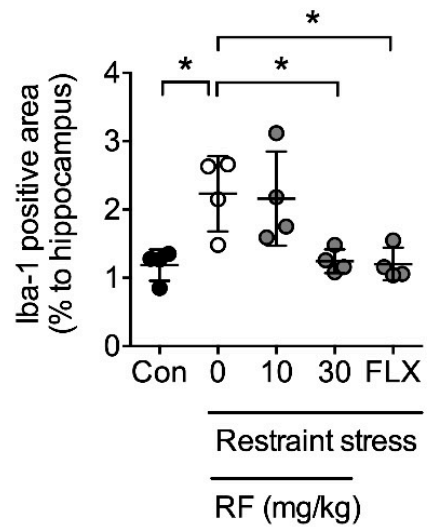

Figure 4. Effect of rubrofusarin on neuroinflammation: (A) Photomicroscopic image of Iba-1-immunopositive cells in the hippocampus. Bar $=100 \mu \mathrm{m}$. (B) Quantitative analysis of Iba-1-immunopositive area in the hippocampus. Data represented as mean \pm SD with raw data. * $p<0.05$.

A

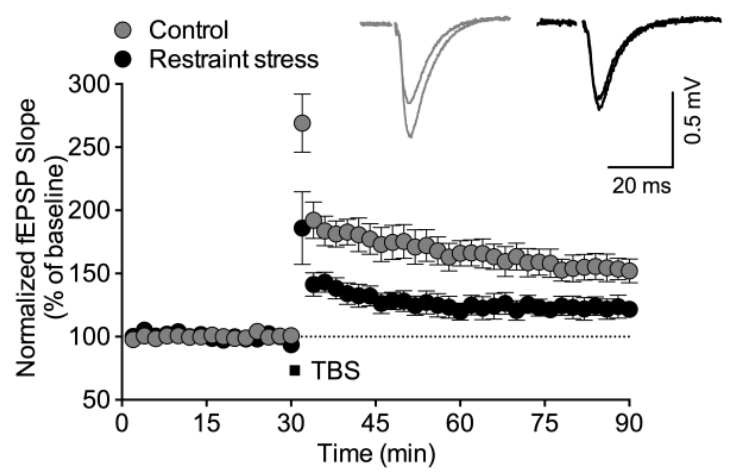

C

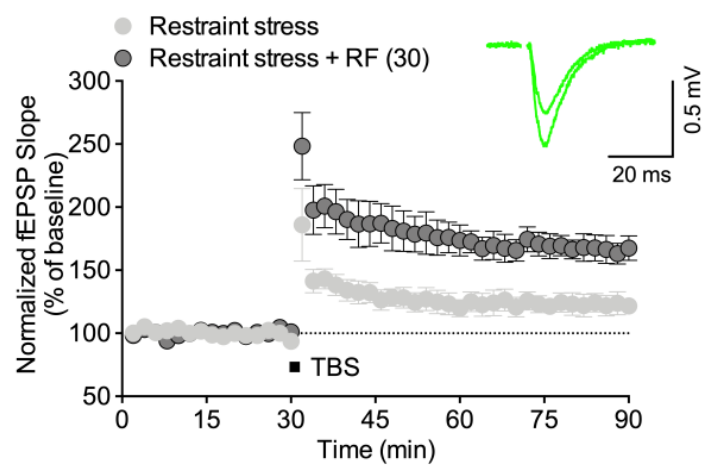

B

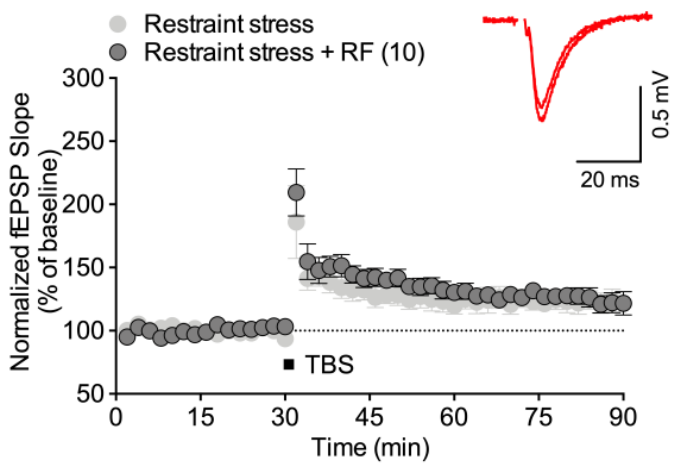

D

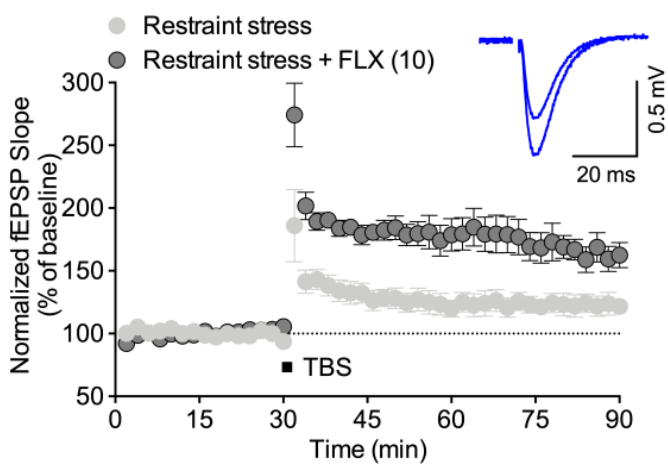

Figure 5. Effect of rubrofusarin on synaptic deficit: Long-term potentiation in the Schaffer-collateral pathway was induced by 2 trains of theta burst stimulation (TBS, 5 trains of 4 pulses at $100 \mathrm{~Hz}$ ) after 30 min stable baseline. (A) Normalized Field excitatory postsynaptic potential (fEPSP) slop of control and chronic restraint stress (CRS) group for $90 \mathrm{~min}$. (B) Normalized fEPSP slop of CRS + rubrofusarin (10 $\mathrm{mg} / \mathrm{kg}$ ) group for $90 \mathrm{~min}$. (C) Normalized fEPSP slop of control and CRS + rubrofusarin (30 mg/kg) group for $90 \mathrm{~min}$. (D) Normalized fEPSP slop of CRS + fluoxetine $(10 \mathrm{mg} / \mathrm{kg})$ group for $90 \mathrm{~min}$. Data represented as mean $\pm \mathrm{SD}$. 


\subsection{Rubrofusarin Blocked Corticosterone-Induced LTP Impairment Through Regulating the Akt Signaling}

To examine the underlying mechanism of rubrofusarin, we tested rubrofusarin in corticosterone-induced LTP impairments in the acute hippocampal slices (Figure 6A). Corticosterone (CORT, $1 \mu \mathrm{M}$ ) suppressed Theta burst stimulation (TBS)-induced LTP induction (Figure 6B,G). RF (30 and $100 \mu \mathrm{M})$ blocked this CORT-induced LTP deficit in a concentration-dependent manner $(\mathrm{F} 5,27=7.453$, $p<0.05, n=5-6 /$ group, Figure 6C-G). Moreover, suppression of Akt signaling with LY294002 but not ERK signaling with U0126 blocked the effect of RF $(p<0.05$, Figure 7A-D). These results suggest that Akt signaling might be required for the effect of RF on CORT-induced LTP impairment.

A

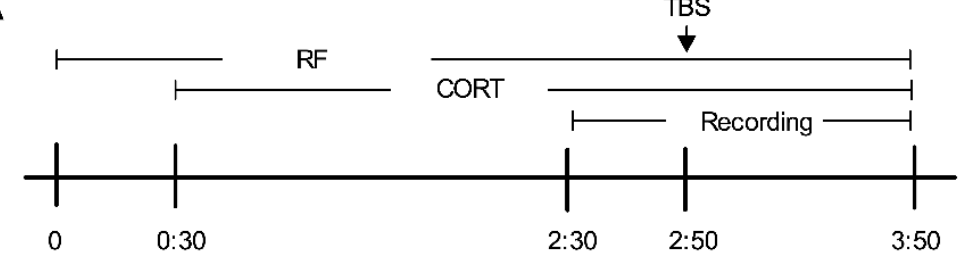

B

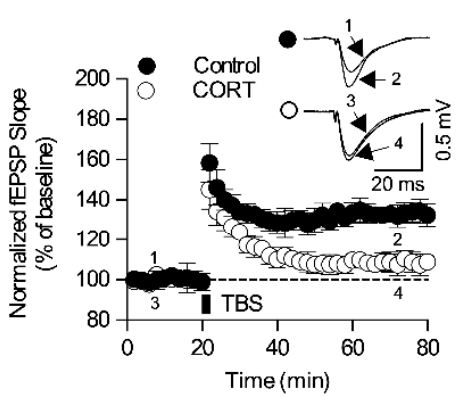

$\mathrm{E}$

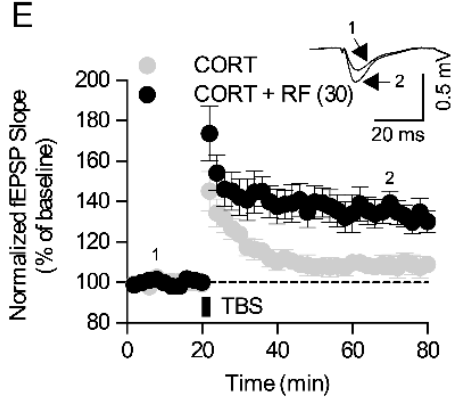

C

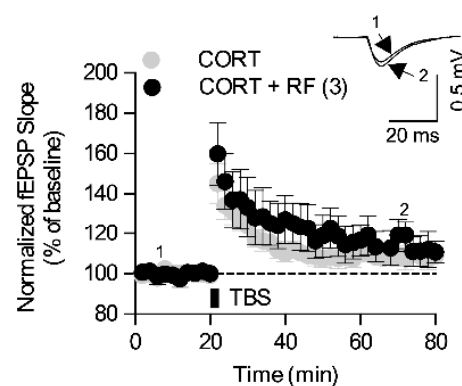

$\mathrm{F}$

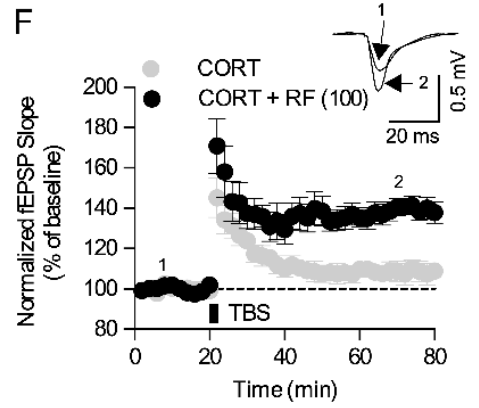

$\mathrm{D}$

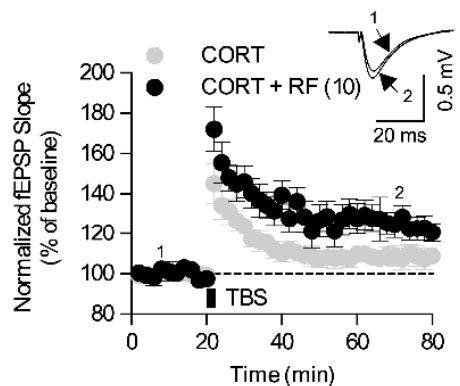

G

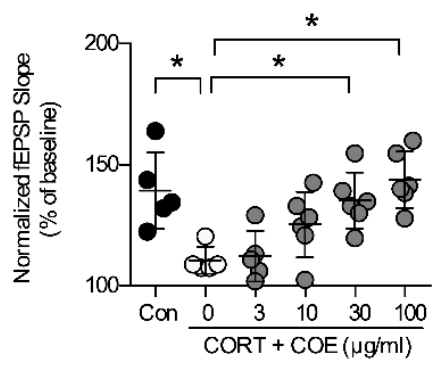

Figure 6. Effect of rubrofusarin on corticosterone-induced synaptic deficit: (A) Schematic diagram of experimental schedule. Hippocampal slices were treated with rubrofusarin (RF) from 30 min before corticosterone (CORT) treatment. HFS was delivered to the slices $30 \mathrm{~min}$ after the CORT treatment. (B) Normalized fEPSP slop of control and CORT $(1 \mu \mathrm{M})$ group for $80 \mathrm{~min}$. (C) Normalized fEPSP slop of CORT + RF $(3 \mu \mathrm{M})$ group for $80 \mathrm{~min}$. (D) Normalized fEPSP slop of CORT + RF $(10 \mu \mathrm{M})$ group for 80 min. (E) Normalized fEPSP slop of CORT + RF (30 $\mu \mathrm{M})$ group for $80 \mathrm{~min}$. (F) Normalized fEPSP slop of CORT + RF $(100 \mu \mathrm{M})$ group for $80 \mathrm{~min}$. Data represented as mean \pm SD. (G) Normalized fEPSP slop of each group during last $10 \mathrm{~min}$. Data represented as mean $\pm \mathrm{SD}$ with raw data. ${ }^{*} p<0.05$. 
A
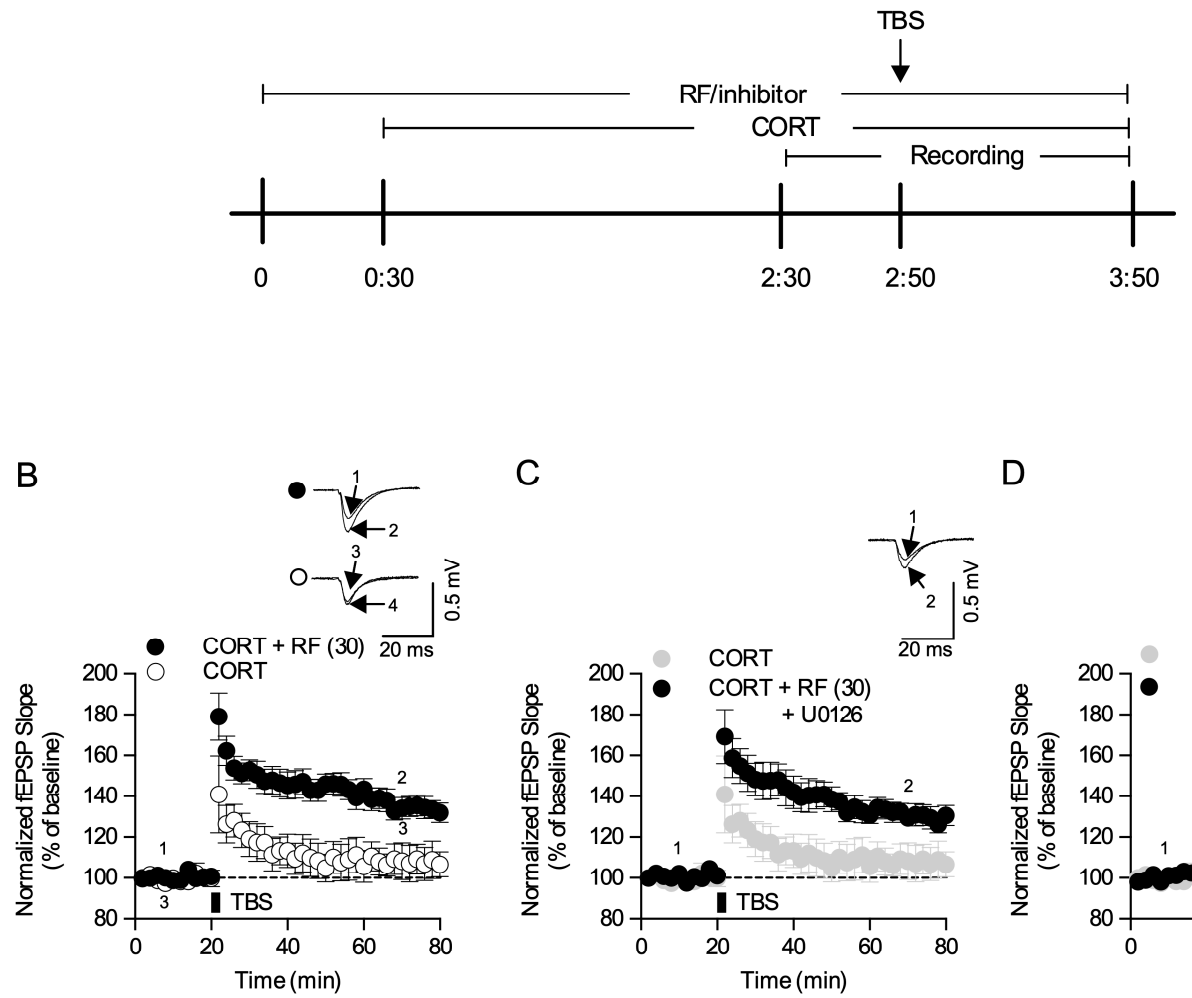

D

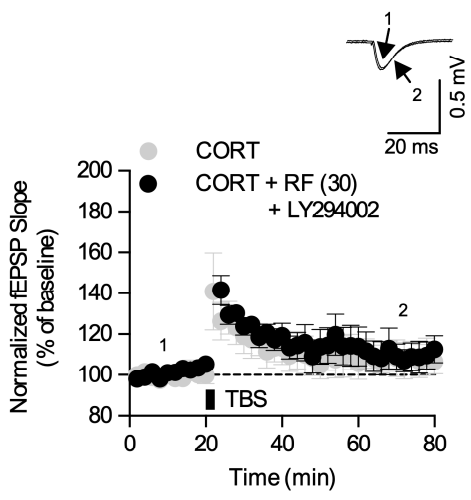

Figure 7. The role of Akt/GSK-3ß signaling in the effect of rubrofusarin synaptic deficit: (A) Hippocampal slices were co-treated with rubrofusarin (RF) and inhibitors. Corticosterone $(1 \mu \mathrm{M}$, CORT) was introduced to the slices $30 \mathrm{~min}$ after RF treatment. Theta burst stimulation (TBS, 5 trains of 4 pulses at $100 \mathrm{~Hz}$ ) was delivered to the slices $30 \mathrm{~min}$ after the CORT treatment. (B) Normalized fEPSP slop of CORT + RF $(30 \mu \mathrm{M})$ and CORT group for $80 \mathrm{~min}$. (C) Normalized fEPSP slop of CORT + $\mathrm{RF}(30 \mu \mathrm{M})+\mathrm{U} 0126(50 \mu \mathrm{M})$ group for $80 \mathrm{~min}$. (D) Normalized fEPSP slop of CORT + RF (30 $\mu \mathrm{M})+$ LY294002 $(50 \mu \mathrm{M})$ group for $80 \mathrm{~min}$. Data represented as mean \pm SD.

\subsection{Akt Signaling Was Required for the Antidepressive Effect of Rubrofusarin}

To test whether Akt/glycogen synthase kinase-3 (GSK-3) signaling is involved in the antidepressive effects of rubrofusarin, LY294002 (LY) was injected into the third ventricle through the cannulae to block Akt/GSK-3-signaling. Neither treatments affected total exploration time during training session of the object recognition test $(\mathrm{F} 4,45=2.419, p>0.05, n=10$ /group, Figure $8 \mathrm{~A})$. The effect of RF on stress-induced decreases of the discrimination ratio was blocked with LY (F4,45 $=24.77, p<0.05$, $n=10$ /group, Figure 8B). The effect of RF on stress-induced reductions in time spent in the center zone of the open field was also blocked by LY (F4,45 $=75.53, p<0.05, n=10$ /group, Figure 8C). In terms of immobility time during the forced swimming test, LY blocked the effect of RF, as well ( $F 4,45=11.60$, $p<0.05, n=10$ /group, Figure 8D). These behavioral results suggest that the antidepressive effect of RF might require activation of Akt/GSK-3 signaling. 
A
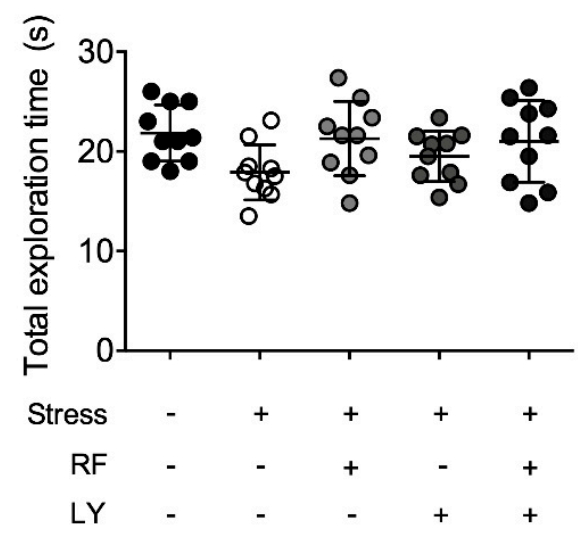

C

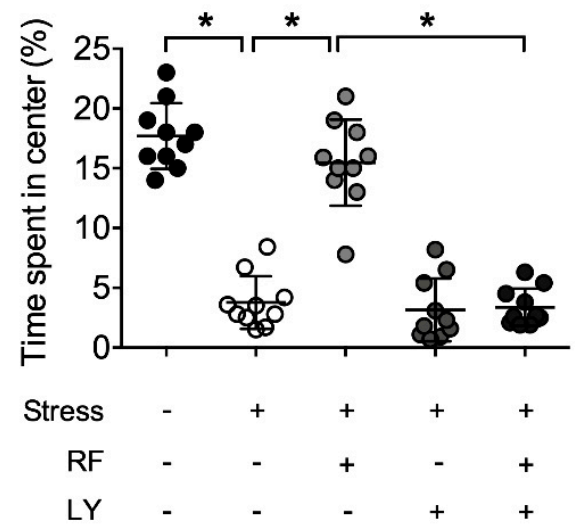

B

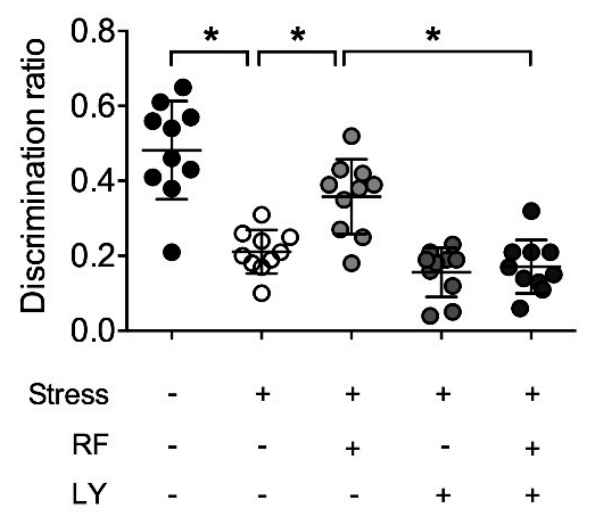

D

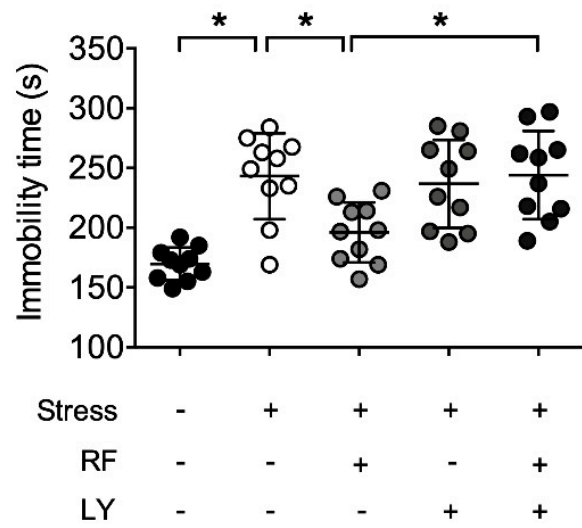

Figure 8. Effect of LY294002 on the effect of rubrofusarin on depressive symptoms: Mice were treated with LY204002 (1 nmol, $3 \mu \mathrm{L}$, intracerebroventricular injection (i.c.v.)) $30 \mathrm{~min}$ before rubrofusarin treatment. Rubrofusarin was administered to mice $1 \mathrm{~h}$ before restraint stress protocol. (A) Total exploration time for objects in training trial of object recognition test. (B) Discrimination ration in test trial of object recognition test. (C) Time spent in center of open field in the habituation trial of object recognition test. (D) Immobility time in forced swimming test. Data represented as mean \pm SD with raw data. ${ }^{*} p<0.05$.

To test whether Akt/GSK-3-signaling is also required for the effects of rubrofusarin on stress-induced synaptic deficits, LTP in the hippocampus was measured (Figure 9A-F). LY treatment blocked RF-restoring LTP impairment in the stress-treated hippocampus $(\mathrm{F} 4,25=7.738, p<0.05, n=7$ (7 slices from 3-4 mice)/group, Figure 9A-F). 
A

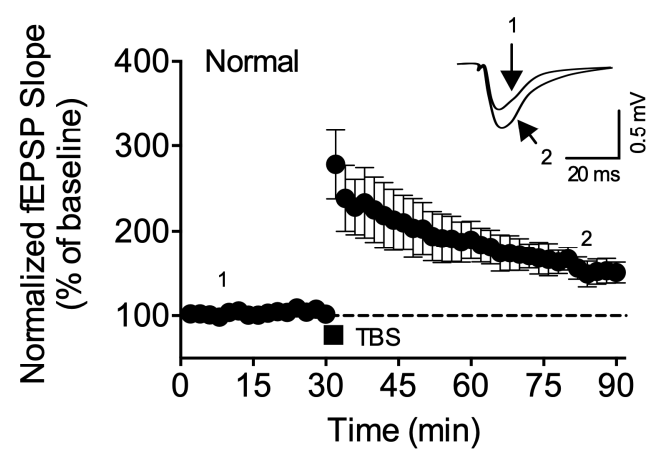

C
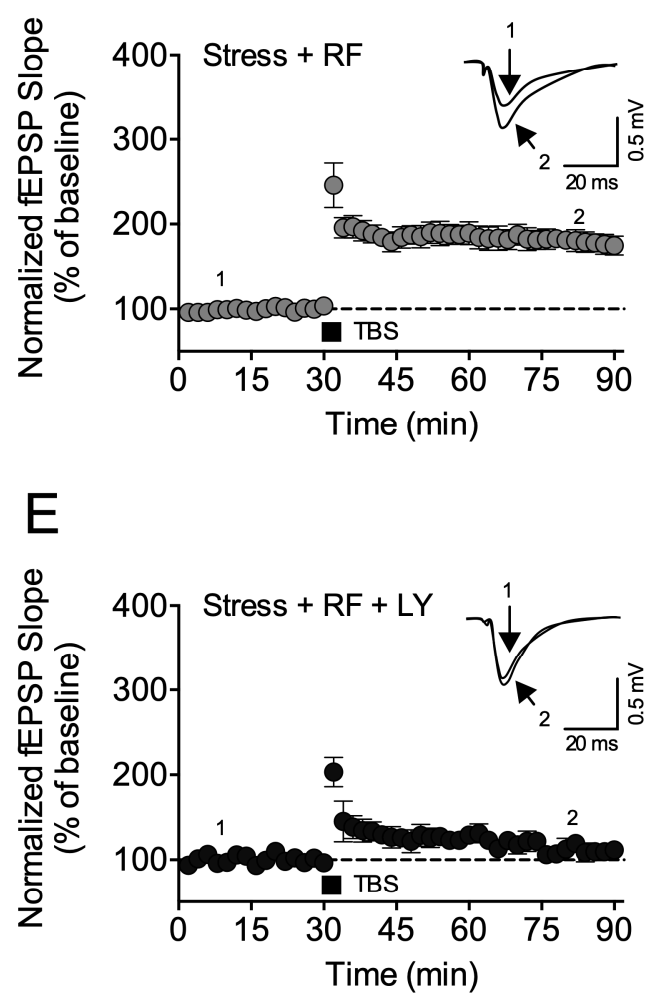

B
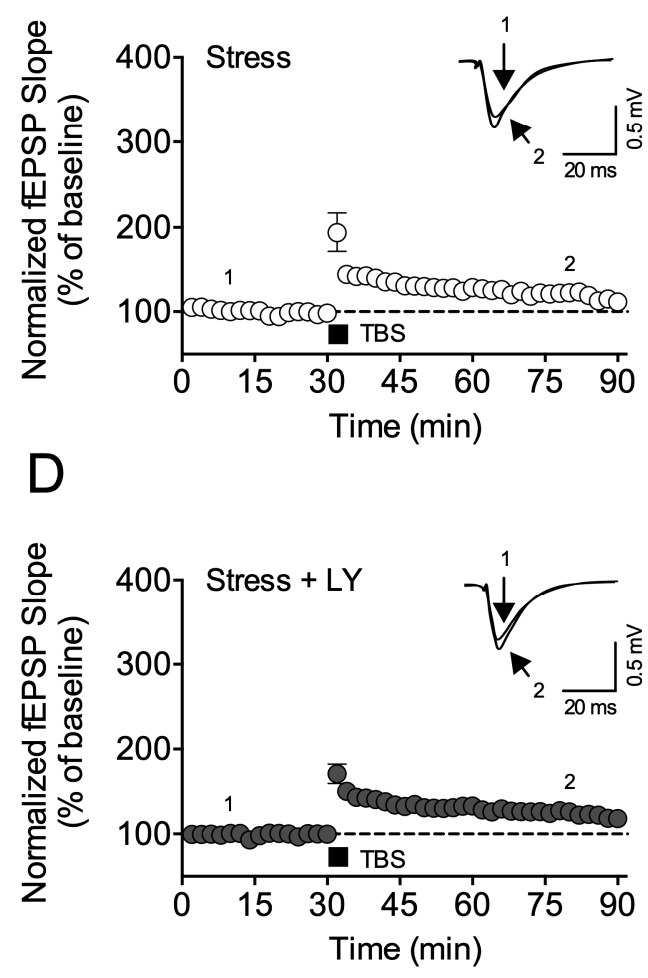

$\mathrm{F}$

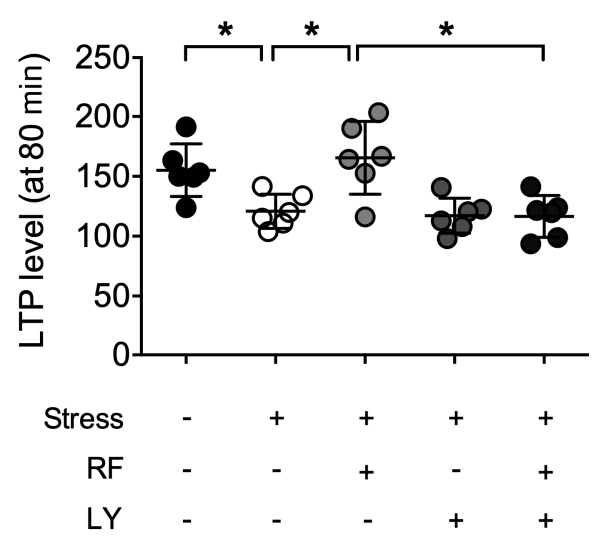

Figure 9. Effect of LY294002 on the effect of rubrofusarin on synaptic deficit: Long-term potentiation in the Schaffer-collateral pathway was induced by theta burst stimulation (TBS, 5 trains of 4 pulses at $100 \mathrm{~Hz}$ ) after $30 \mathrm{~min}$ stable baseline. (A) Normalized fEPSP slop of normal group for $90 \mathrm{~min}$. (B) Normalized fEPSP slop of CRS (stress) group for $90 \mathrm{~min}$. (C) Normalized fEPSP slop of stress + RF (30 mg/kg) group for 90 min. (D) Normalized fEPSP slop of stress + LY294002 (LY, $1 \mathrm{nmol}, 3 \mu \mathrm{L}$, i.c.v.) group for $90 \mathrm{~min}$. (E) Normalized fEPSP slop of stress + RF $(30 \mathrm{mg} / \mathrm{kg})+\mathrm{LY}(1 \mathrm{nmol}, 3 \mu \mathrm{L}$, i.c.v.) group for $90 \mathrm{~min}$. Data represented as mean \pm SD. (F) Normalized fEPSP slop of each group during last $10 \mathrm{~min}$. Data represented as mean $\pm \mathrm{SD}$ with raw data. ${ }^{*} p<0.05$.

\section{Discussion}

In the present study, we found that chronic treatment of rubrofusarin ameliorated CRS-induced depressive symptoms. Rubrofusarin blocked CRS-induced neurodegeneration and reduction in neurogenesis within the hippocampus. CRS-induced neuroinflammation was blocked by rubrofusarin. Dysfunctions in hippocampal synaptic plasticity were also rescued by rubrofusarin treatment. Within 
the in vitro experiments, rubrofusarin blocked corticosterone (CORT)-induced LTP impairments through regulating Akt signaling. Additionally, Akt inhibition blocked rubrofusarin-ameliorated CRS-induced depressive symptoms.

Stress is thought to be a major environmental trigger for individuals with clinical depression $[29,30]$. Stress can stimulate release of norepinephrine and glucocorticoid from the adrenal glands, which induce stress-related coping responses [31,32]. However prolonged stress, which can induce constant high levels of blood glucocorticoid and long-term stimulation in nervous system by norepinephrine, can cause harmful effects in the brain $[33,34]$. Pharmacological long-term elevations in corticosterone can induce depressive symptoms including depressive behaviors and neurochemical changes in mice. Glucocorticoid receptor (GR) antagonist blocked stress-induced depressive symptoms [35,36]. However, direct regulation of steroid receptors may cause unpredictable side effects including abnormal negative feedback of steroid hormones.

Chronic stress induced neuronal degeneration [37,38]. Although the precise mechanism is not clear, prolonged increases of corticosterone levels may induce abnormal activation of the $N$-methyl-D-aspartate receptor (NMDAR), which can increase intracellular $\mathrm{Ca}^{2+}$ levels $[39,40]$. Increased intracellular $\mathrm{Ca}^{2+}$ levels may activate caspase- 3 through calpain, $\mathrm{a} \mathrm{Ca}^{2+}$-sensing protease [41,42], thereby triggering neuronal death signals. In the present study, we found that CRS induced neuronal degeneration in the hippocampal DG region. Moreover, CRS increased active-caspase-3 levels in the hippocampus. These results suggest that CRS may induce neuronal degeneration and that this might be related to caspase-3 activation in the hippocampus. Rubrofusarin blocked CRS-induced neuronal degeneration.

Neurogenesis is believed to be the mechanism underlying learning and memory in the hippocampus $[43,44]$. Neurogenesis is decreased in various animal models of depression and within the depressed patient's brain $[45,46]$. Chronic stress can suppress neurogenesis through suppression of phosphoinositide 3-kinases (PI3K)/Akt signaling [47]. Activation of GSK-3 $\beta$ is also involved in stress-related suppression of neurogenesis $[48,49]$. Lithium, a GSK-3 inhibitor, showed antidepressive effects and restored neurogenesis [50]. Moreover, many FDA-approved antidepressants including fluoxetine and venlafaxine also restored suppressed neurogenesis in depression models, suggesting that regulation of neurogenesis is an important action of antidepressants [51]. In the present study, we found that CRS suppressed neurogenesis and that rubrofusarin blocked this in the hippocampus.

Neuroinflammation is additionally a major underlying mechanism of depression. Chronic stress-activated microglia have been studied as key mediators for the onset of brain diseases [52,53]. Recent studies show that the nod-like receptor family pyrin domain containing 3 (NLRP3) inflammasome is upregulated in microglia and may play an important role in depression [54]. Moreover, studies show NLRP3 inflammasome activation in animal models of depression [55] as well as in patients with depression [56]. Silymarin showed antidepressive effects through regulation of NLRP3 inflammasome activation [57,58]. P2X7 receptor and NLRP inflammasome activation in the hippocampus were involved in chronic stress-induced onset of depressive symptoms [58]. Glucocorticoid-induced NLRP3 inflammasome activation in the hippocampal microglia might mediate chronic stress-induced depressive symptoms [55]. These suggest that the NLRP3 inflammasome might be a novel target for antidepressants. In the present study, CRS induced microglial activation and increased NLRP3 inflammasomes in the hippocampus. Rubrofusarin suppressed CRS-induced these neuroinflammation.

Recently, it was found that corticosterone suppressed hippocampal synaptic plasticity through activation of caspase-3 [59]. Chronic glucocorticoid receptor (GR) activation may induce synaptic depression through caspase-3 activation, which might be mediated by abnormal activation of NMDAR [60,61]. GR-induced synaptic depression may be a phenomenon of the depressed brain $[6,62,63]$. Antidepressants ameliorated this synaptic depression through various mechanisms. In the present study, CRS caused synaptic deficits in the hippocampus. Oral administration of rubrofusarin blocked CRS-induced synaptic deficits. Moreover, corticosterone, by itself, caused 
synaptic deficits within the hippocampal slices. Rubrofusarin ameliorated corticosterone-induced synaptic deficits through regulation of Akt/GSK-3 $\beta$ signaling.

Rubrofusarin blocked various CRS-induced depressive symptoms including behavioral and synaptic deficits and neuroinflammation. These results may indicate that rubrofusarin has antidepressive, anti-neurodegenerative, and anti-neuroinflammation effects. Otherwise, rubrofusarin may act as a blocker of upper stream signals, which are activated by CRS, such as GR $[64,65]$. In the present study, we found that Akt/GSK-3 $\beta$ signaling is implicated in the various effects of rubrofusarin. GR activation can suppress Akt, resulting in GSK-3 $\beta$ activation $[59,66]$. Activation of GSK-3 $\beta$ is implicated in neurogenesis [67], synaptic deficits [68], and neuroinflammation [69]. Therefore, rubrofusarin inhibited GSK-3 $\beta$ resulting in amelioration of various symptoms including neurogenesis, synaptic deficits, and neuroinflammation.

In conclusion, rubrofusarin blocked CRS-induced onset of depressive disorder through inhibiting Akt-relating signaling. These results suggest that rubrofusarin may be a needed compound for developing antidepressant. However, we still do not know whether rubrofusarin inhibits Akt activity directly or indirectly. To elucidate this, further study will be needed.

\section{Materials and Methods}

\subsection{Animals}

CD-1 mice weighing 25-30 g (male, 6-week-old) were purchased from Samtako (Osan, Korea). The mice were habituated to the living environment for 1 week before each experiment. Five mice were housed in one cage and were provided water and food ad libitum (temperature, $23 \pm 1{ }^{\circ} \mathrm{C}$; humidity, $60 \pm 10 \%$ ) under a $12 \mathrm{~h}$ illumination cycle (lights on from 07:30 to 19:30). Animal treatments and maintenance were carried out in accordance with the Animal Care and Use Guidelines issued by Dong-A University, Republic of Korea. All experimental protocols using mice were approved by the Institutional Animal Care and Use Committee of Dong-A University (approval number, DIACUC-approve-19-33, 10/12/2019).

\subsection{Restraint Stress}

Using clear plastic tube ( $3 \mathrm{~cm}$ in diameter and $10 \mathrm{~cm}$ in length) having many holes for ventilation, restraint stress was introduced to mice for $4 \mathrm{~h}$ per day for 11 days restraint from 10:00 a.m. to 2:00 p.m. Mice are able to move anterior limbs and the head but not the body. The control group (nonrestraint mice) stayed in the home cages until the object recognition test started. Behavioral tests were started 1 $\mathrm{h}$ after the 4 -h period of restraint stress.

\subsection{Objective Recognition Memory Test}

Habituation of mice to open field (cube shape with $25 \mathrm{~cm}^{3}$ ) was conducted for $10 \mathrm{~min}$. During habituation, time spent in center $(5 \mathrm{~cm} \times 5 \mathrm{~cm})$ was measured for analyzing anxiety state of the mice. Thirty minutes later, mice were placed in the same open field with two same objects (two glass boxes). Total exploration time was measured during training. After $24 \mathrm{~h}$, mice were return to the same open field for testing. The two different objects (glass box and crystal cylinder) were again present. Mice were allowed to freely explore the environment and the objects for $5 \mathrm{~min}$. Total time spent exploring the novel (Tnovel) and familiar (Tfamiliar) objects were measured. Discrimination ratio was calculated by the following formula: Tnovel - Tfamiliar/(Tnovel + Tfamiliar).

\subsection{Forced Swimming Test}

Using a clear glass cylinder ( $25 \mathrm{~cm}$ in height and $14 \mathrm{~cm}$ in diameter) containing water $\left(24 \pm 2{ }^{\circ} \mathrm{C}\right)$, the forced swimming test was performed for $6 \mathrm{~min}$ in a dim environment. Their immobility times were recorded using the video-based Ethovision System (Noldus Information Technology B.V., Wageningen, Netherlands) during the last $4 \mathrm{~min}$ of the 6 min test. 


\subsection{Tissue Slices Preparation}

Mice were anesthetized using isoflurane (3\%) immediately after the forced swimming test. Transcardial perfusion was conducted with $100 \mathrm{mM}$ phosphate buffered saline (PBS, pH 7.4) followed by ice-cold $4 \%$ paraformaldehyde. Then, isolated brains were postfixed in PBS containing $4 \%$ paraformaldehyde for $12 \mathrm{~h}$. Then, the brains were stored in a sucrose solution ( $30 \%$ in $50 \mathrm{mM}$ PBS, $4{ }^{\circ} \mathrm{C}$ ). Coronal sections including the hippocampus were stored in a storage solution at $4{ }^{\circ} \mathrm{C}$.

\subsection{Floro-Jade B Staining}

Fluoro-Jade B staining was conducted to label degenerating cells. Coronal sections mounted on gelatin-coated slide glass were incubated in $0.06 \%$ potassium permanganate for $15 \mathrm{~min}$. The sections were rinsed for $1 \mathrm{~min}$ in distilled water (DW) and then incubated in the Fluoro-Jade B staining solution $(0.0001 \% \mathrm{wt} / \mathrm{vol}$ in distilled water containing $0.1 \%$ acetic acid) for $30 \mathrm{~min}$ and rinsed with DW for 3 times. The slides were incubated in $100 \%$ of xylene and then coverslipped with Dibutylphthalate Polystyrene Xylene mounting media (Sigma-Aldrich, Saint Louis, MO, USA). The number of Fluoro-Jade-B-positive cells in the hippocampal dentate gyrus was measured. Only positive neurons with a near-complete cell body shape and size were counted. Cell counts were expressed as the total number of Fluoro-Jade-positive cells per section.

\subsection{Immunohistochemistry}

Primary antibodies including goat anti-doublecortin or rat anti-iba- 1 antibody (1:1000 dilution) were mixed with $0.3 \%$ Triton X-100 and $1.5 \%$ normal serum. Free-floating sections were incubated for $24 \mathrm{~h}$ in $\mathrm{PBS}\left(4^{\circ} \mathrm{C}\right)$ containing primary solution. After washing, the sections were treated with biotinylated secondary antibody (1:1000 dilution) for $90 \mathrm{~min}$ and then incubated in an avidin-biotin-peroxidase complex (1:100 dilution, $1 \mathrm{~h}$, room temperature). After washing, the sections were incubated in 3 , 3'-diaminobenzidine solution $\left(0.02 \%\right.$ in DW containing $\left.0.01 \% \mathrm{H}_{2} \mathrm{O}_{2}, 3 \mathrm{~min}\right)$. Finally, the sections were mounted on gelatin-coated slides. Then the slides were dehydrated in an ascending alcohol series $(75 \%, 90 \%, 95 \%$, and $100 \%)$ and cleared in xylene. Only near-complete cell body shape and size were counted. Cell counts were expressed as the total number of doublecortin-positive cells per section. Iba-1-immunopositive area was analyzed with ImageJ software.

\subsection{Hippocampal Slices Preparation and Electrophysiology}

Artificial cerebrospinal fluid (ACSF) is composed with $\mathrm{NaCl}(124 \mathrm{mM}), \mathrm{KCl}(3 \mathrm{mM}), \mathrm{NaHCO}_{3}$ (26 mM), $\mathrm{NaH}_{2} \mathrm{PO}_{4}(1.25 \mathrm{mM}), \mathrm{CaCl}_{2}(2 \mathrm{mM}), \mathrm{MgSO}_{4}(1 \mathrm{mM})$, and D-glucose (10 mM). We rapidly isolated the hippocampus and submerged it in chilled ACSF. For tissue slicing, we used McIlwain tissue chopper; $400-\mu \mathrm{m}$-thick hippocampal slices were incubated in ACSF $\left(20-25^{\circ} \mathrm{C}, 2 \mathrm{~h}\right)$ before the experiment.

Field excitatory postsynaptic potential (fEPSP) was recorded in the CA1 area (Schaffer-collateral-commissural pathway). Constant stimuli were delivered through stimulating electrode $(0.033 \mathrm{~Hz})$. The slope of the evoked fEPSP was averaged over consecutive recordings evoked at $30 \mathrm{~s}$ intervals; $30 \mathrm{~min}$ after the initiation of a stable baseline, theta burst stimulations (TBS: 5 trains of 4 pulses at $100 \mathrm{~Hz}$ ) were introduced to induce long-term potentiation (LTP). LTP was quantified by comparing the mean fEPSP slope at 80 min after the TBS with the mean fEPSP slope during the baseline period.

\subsection{Microinfusion of Drugs}

Mice were placed in a stereotaxic frame (David Kopf Instruments, Los Angeles, CA, USA) under isoflurane anesthesia (induction $3 \%$ and maintenance $2 \%$ ), and guide cannulae (26G) was aimed at the right lateral ventricle ( $\mathrm{AP},-0.02 \mathrm{~mm}$ from bregma; $\mathrm{ML},-0.80 \mathrm{~mm}$ from midline; $\mathrm{DV},-2.50 \mathrm{~mm}$ from the dura) based on atlas of the mouse brain [70]. The guide cannulae were fixed to the skull 
with dental cement and covered with dummy cannulae. Following surgery, mice were allowed to recover for 7 days. LY294002 was dissolved in $0.1 \%$ dimethyl sulfoxide in saline $(0.9 \% \mathrm{NaCl})$ before infusion. Fifteen minutes before the oral administration of rubrofusarin, mice were carefully restrained by hand and infused with LY294002 $(1 \mathrm{nmol}, 3 \mu \mathrm{L}$ ) or vehicle through injector cannulae (30 G) extended $1.0 \mathrm{~mm}$ beyond the tips of guide cannulae. The infusion volume was $3 \mu \mathrm{L}$, and the infusion rate was $0.5 \mu \mathrm{L} / \mathrm{min}$. After the infusion, the infusion needle was left in the guide cannula for $1 \mathrm{~min}$ to ensure proper delivery of the reagents.

\subsection{Statistics}

The results of all experiments were analyzed with one-way ANOVA followed by Turkey's test for multiple comparisons. Student's t-test was used to compare two groups. The values are expressed as the means $\pm \mathrm{SD}$ with raw data; $p<0.05$ was considered significant.

Author Contributions: Conceptualization, J.H.C. and D.H.K.; methodology, E.C. and J.Y.; formal analysis, J.H.Y., J.J., and H.K.; investigation, J.H.Y. and J.J.; data curation, Y.C.L. and J.H.R.; writing-original draft preparation, J.H.Y. and H.K.; writing - review and editing, J.H.C. and D.H.K.; visualization, S.J.P. and D.H.K.; supervision, J.H.C. and K.D.H.; funding acquisition, J.H.C. and K.D.H. All authors have read and agreed to the published version of the manuscript.

Funding: This study was funded by the National Research Foundation of Korea (NRF) grant funded by the Korea government (MEST) (2019R1I1A3A01061630 and 2016R1A5A2007009) and BB21 + program.

Conflicts of Interest: The authors declare no conflict of interest.

$\begin{array}{ll}\text { Abbreviations } \\ \text { CRS } & \text { Chronic restraint stress } \\ \text { REDD1 } & \text { Regulated in development and DNA damage responses 1 } \\ \text { NLRP3 } & \text { Nod-like receptor family pyrin domain containing 3 } \\ \text { GSK-3 } & \text { Glycogen synthase kinase-3 } \\ \text { PI3K } & \text { Phosphoinositide 3-kinases } \\ \text { ACSF } & \text { Artificial cerebrospinal fluid } \\ \text { fEPSP } & \text { Field excitatory postsynaptic potential } \\ \text { TBS } & \text { Theta burst stimulation } \\ \text { LTP } & \text { Long-term potentiation } \\ \text { RF } & \text { Rubrofusarin } \\ \text { FLX } & \text { Fluoxetine } \\ \text { DG } & \text { Dentate gyrus } \\ \text { CORT } & \text { Corticosterone } \\ \text { NMDAR } & \text { N-methyl-D-aspartate receptor } \\ \text { GR } & \text { Glucocorticoid receptor }\end{array}$

\section{References}

1. Pardon, M.C.; Gould, G.G.; Garcia, A.; Phillips, L.; Cook, M.C.; Miller, S.A.; Mason, P.A.; Morilak, D.A. Stress reactivity of the brain noradrenergic system in three rat strains differing in their neuroendocrine and behavioral responses to stress: Implications for susceptibility to stress-related neuropsychiatric disorders. Neuroscience 2002, 115, 229-242. [CrossRef]

2. Hall, B.S.; Moda, R.N.; Liston, C. Glucocorticoid Mechanisms of Functional Connectivity Changes in Stress-Related Neuropsychiatric Disorders. Neurobiol. Stress 2015, 1, 174-183. [CrossRef] [PubMed]

3. Dunn, A.J.; Swiergiel, A.H.; Palamarchouk, V. Brain circuits involved in corticotropin-releasing factor-norepinephrine interactions during stress. Ann. N. Y. Acad. Sci. 2004, 1018, 25-34. [CrossRef] [PubMed]

4. Bremner, J.D. Traumatic stress: Effects on the brain. Dialogues Clin. Neurosci. 2006, 8, 445-461. [PubMed]

5. Kashihara, K.; Maruyama, T.; Murota, M.; Nakahara, Y. Positive effects of acute and moderate physical exercise on cognitive function. J. Physiol. Anthropol. 2009, 28, 155-164. [CrossRef] 
6. Pittenger, C.; Duman, R.S. Stress, depression, and neuroplasticity: A convergence of mechanisms. Neuropsychopharmacology 2008, 33, 88-109. [CrossRef]

7. Burke, H.M.; Davis, M.C.; Otte, C.; Mohr, D.C. Depression and cortisol responses to psychological stress: A meta-analysis. Psychoneuroendocrinology 2005, 30, 846-856. [CrossRef]

8. Bruno, A.; Celebre, L.; Mento, C.; Rizzo, A.; Silvestri, M.C.; De Stefano, R.; Zoccali, R.A.; Muscatello, M.R.A. When Fathers Begin to Falter: A Comprehensive Review on Paternal Perinatal Depression. Int. J. Environ. Res. Public Health 2020, 17, 1139. [CrossRef]

9. Thomson, K.C.; Romaniuk, H.; Greenwood, C.J.; Letcher, P.; Spry, E.; Macdonald, J.A.; McAnally, H.M.; Youssef, G.J.; McIntosh, J.; Hutchinson, D.; et al. Adolescent antecedents of maternal and paternal perinatal depression: A 36-year prospective cohort. Psychol. Med. 2020, 1-8. [CrossRef]

10. Ossowska, G.; Nowa, G.; Kata, R.; Klenk-Majewska, B.; Danilczuk, Z.; Zebrowska-Lupina, I. Brain monoamine receptors in a chronic unpredictable stress model in rats. J. Neural Transm. 2001, 108, 311-319. [CrossRef]

11. Hamon, M.; Blier, P. Monoamine neurocircuitry in depression and strategies for new treatments. Prog. Neuropsychopharmacol. Biol. Psychiatry 2013, 45, 54-63. [CrossRef] [PubMed]

12. Cascade, E.; Kalali, A.H.; Kennedy, S.H. Real-World Data on SSRI Antidepressant Side Effects. Psychiatry (Edgmont) 2009, 6, 16-18.

13. Ferguson, J.M. SSRI Antidepressant Medications: Adverse Effects and Tolerability. Prim Care Companion J. Clin. Psychiatry 2001, 3, 22-27. [CrossRef] [PubMed]

14. Cartwright, C.; Gibson, K.; Read, J.; Cowan, O.; Dehar, T. Long-term antidepressant use: Patient perspectives of benefits and adverse effects. Patient Prefer. Adherence 2016, 10, 1401-1407. [CrossRef]

15. Delgado, P.L. Depression: The case for a monoamine deficiency. J. Clin. Psychiatry 2000, 61 (Suppl. 6), 7-11. [PubMed]

16. Bottiglieri, T.; Laundy, M.; Crellin, R.; Toone, B.K.; Carney, M.W.; Reynolds, E.H. Homocysteine, folate, methylation, and monoamine metabolism in depression. J. Neurol. Neurosurg. Psychiatry 2000, 69, 228-232. [CrossRef]

17. Wang, S.M.; Han, C.; Bahk, W.M.; Lee, S.J.; Patkar, A.A.; Masand, P.S.; Pae, C.U. Addressing the Side Effects of Contemporary Antidepressant Drugs: A Comprehensive Review. Chonnam Med. J. 2018, 54, 101-112. [CrossRef]

18. Arroll, B.; Chin, W.Y.; Martis, W.; Goodyear-Smith, F.; Mount, V.; Kingsford, D.; Humm, S.; Blashki, G.; MacGillivray, S. Antidepressants for treatment of depression in primary care: A systematic review and meta-analysis. J. Prim Health Care 2016, 8, 325-334. [CrossRef]

19. Han, Y.H.; Kee, J.Y.; Park, S.H.; Mun, J.G.; Jeon, H.D.; Park, J.; Zou, Q.P.; Liu, X.Q.; Hong, S.H. Rubrofusarin-6-beta-gentiobioside inhibits lipid accumulation and weight gain by regulating AMPK/mTOR signaling. Phytomedicine 2019, 62, 152952. [CrossRef]

20. Xiao, J.; Zhang, Q.; Gao, Y.Q.; Shi, X.W.; Gao, J.M. Antifungal and antibacterial metabolites from an endophytic Aspergillus sp. associated with Melia azedarach. Nat. Prod. Res. 2014, 28, 1388-1392. [CrossRef]

21. Lee, H.J.; Jung, J.H.; Kang, S.S.; Choi, J.S. A rubrofusarin gentiobioside isomer from roastedCassia tora. Arch. Pharm Res. 1997, 20, 513-515. [CrossRef] [PubMed]

22. Cho, E.; Cai, M.; Kwon, H.; Jeon, J.; Moon, M.; Jun, M.; Lee, Y.C.; Yi, J.H.; Ryu, J.H.; Kim, D.H. Rubrofusarin inhibits Abeta aggregation and ameliorates memory loss in an Abeta-induced Alzheimer's disease-like mouse model. Food Chem. Toxicol. 2019, 132, 110698. [CrossRef] [PubMed]

23. Paudel, P.; Seong, S.H.; Jung, H.A.; Choi, J.S. Rubrofusarin as a Dual Protein Tyrosine Phosphate 1B and Human Monoamine Oxidase-A Inhibitor: An in Vitro and in Silico Study. ACS Omega 2019, 4, 11621-11630. [CrossRef] [PubMed]

24. Schoenfeld, T.J.; McCausland, H.C.; Morris, H.D.; Padmanaban, V.; Cameron, H.A. Stress and Loss of Adult Neurogenesis Differentially Reduce Hippocampal Volume. Biol. Psychiatry 2017, 82, 914-923. [CrossRef]

25. Barha, C.K.; Brummelte, S.; Lieblich, S.E.; Galea, L.A. Chronic restraint stress in adolescence differentially influences hypothalamic-pituitary-adrenal axis function and adult hippocampal neurogenesis in male and female rats. Hippocampus 2011, 21, 1216-1227. [CrossRef]

26. Pan, Y.; Chen, X.Y.; Zhang, Q.Y.; Kong, L.D. Microglial NLRP3 inflammasome activation mediates IL-1beta-related inflammation in prefrontal cortex of depressive rats. Brain Behav. Immun. 2014, 41, 90-100. [CrossRef] 
27. Kreisel, T.; Frank, M.G.; Licht, T.; Reshef, R.; Ben-Menachem-Zidon, O.; Baratta, M.V.; Maier, S.F.; Yirmiya, R. Dynamic microglial alterations underlie stress-induced depressive-like behavior and suppressed neurogenesis. Mol. Psychiatry 2014, 19, 699-709. [CrossRef]

28. Duman, R.S.; Aghajanian, G.K. Synaptic dysfunction in depression: Potential therapeutic targets. Science 2012, 338, 68-72. [CrossRef]

29. Slavich, G.M.; Irwin, M.R. From stress to inflammation and major depressive disorder: A social signal transduction theory of depression. Psychol. Bull. 2014, 140, 774-815. [CrossRef]

30. Breslau, N.; Davis, G.C. Chronic stress and major depression. Arch. Gen. Psychiatry 1986, 43, 309-314. [CrossRef]

31. Tekieh, E.; Riahi, E.; Kazemi, M.; Sahraei, H.; Tavakoli, H.; Aliyary, H.; Hajinasrollah, M.; Salehi, M.; Meftahi, G.; Saberi, M. Role of basal stress hormones and amygdala dimensions in stress coping strategies of male rhesus monkeys in response to a hazard-reward conflict. Iran. J. Basic Med. Sci. 2017, 20, 951-957. [PubMed]

32. Hoglund, E.; Silva, P.I.M.; Vindas, M.A.; Overli, O. Contrasting Coping Styles Meet the Wall: A Dopamine Driven Dichotomy in Behavior and Cognition. Front. Neurosci. 2017, 11, 383. [CrossRef] [PubMed]

33. Alfonso, J.; Frasch, A.C.; Flugge, G. Chronic stress, depression and antidepressants: Effects on gene transcription in the hippocampus. Rev. Neurosci. 2005, 16, 43-56. [CrossRef] [PubMed]

34. Tafet, G.E.; Smolovich, J. Psychoneuroendocrinological studies on chronic stress and depression. Ann. N. Y. Acad. Sci. 2004, 1032, 276-278. [CrossRef] [PubMed]

35. Ago, Y.; Arikawa, S.; Yata, M.; Yano, K.; Abe, M.; Takuma, K.; Matsuda, T. Antidepressant-like effects of the glucocorticoid receptor antagonist RU-43044 are associated with changes in prefrontal dopamine in mouse models of depression. Neuropharmacology 2008, 55, 1355-1363. [CrossRef] [PubMed]

36. Nguyen, E.T.; Caldwell, J.L.; Streicher, J.; Ghisays, V.; Balmer, N.J.; Estrada, C.M.; Solomon, M.B. Differential effects of imipramine and CORT118335 (Glucocorticoid receptor modulator/mineralocorticoid receptor antagonist) on brain-endocrine stress responses and depression-like behavior in female rats. Behav. Brain Res. 2018, 336, 99-110. [CrossRef]

37. Natarajan, R.; Forrester, L.; Chiaia, N.L.; Yamamoto, B.K. Chronic-Stress-Induced Behavioral Changes Associated with Subregion-Selective Serotonin Cell Death in the Dorsal Raphe. J. Neurosci. 2017, 37, 6214-6223. [CrossRef]

38. Vyas, S.; Rodrigues, A.J.; Silva, J.M.; Tronche, F.; Almeida, O.F.; Sousa, N.; Sotiropoulos, I. Chronic Stress and Glucocorticoids: From Neuronal Plasticity to Neurodegeneration. Neural Plast. 2016, 2016. [CrossRef]

39. Nair, A.; Bonneau, R.H. Stress-induced elevation of glucocorticoids increases microglia proliferation through NMDA receptor activation. J. Neuroimmunol. 2006, 171, 72-85. [CrossRef]

40. Takahashi, T.; Kimoto, T.; Tanabe, N.; Hattori, T.A.; Yasumatsu, N.; Kawato, S. Corticosterone acutely prolonged $N$-methyl-D-aspartate receptor-mediated Ca2+ elevation in cultured rat hippocampal neurons. $J$. Neurochem. 2002, 83, 1441-1451. [CrossRef]

41. Rami, A. Ischemic neuronal death in the rat hippocampus: The calpain-calpastatin-caspase hypothesis. Neurobiol. Dis. 2003, 13, 75-88. [CrossRef]

42. Yamashima, T. $\mathrm{Ca}^{2+}$-dependent proteases in ischemic neuronal death: A conserved 'calpain-cathepsin cascade' from nematodes to primates. Cell Calcium 2004, 36, 285-293. [CrossRef] [PubMed]

43. Deng, W.; Aimone, J.B.; Gage, F.H. New neurons and new memories: How does adult hippocampal neurogenesis affect learning and memory? Nat. Rev. Neurosci. 2010, 11, 339-350. [CrossRef] [PubMed]

44. Cameron, H.A.; Glover, L.R. Adult neurogenesis: Beyond learning and memory. Annu. Rev. Psychol. 2015, 66, 53-81. [CrossRef] [PubMed]

45. Hill, A.S.; Sahay, A.; Hen, R. Increasing Adult Hippocampal Neurogenesis is Sufficient to Reduce Anxiety and Depression-Like Behaviors. Neuropsychopharmacology 2015, 40, 2368-2378. [CrossRef]

46. Sahay, A.; Hen, R. Adult hippocampal neurogenesis in depression. Nat. Neurosci. 2007, 10, 1110-1115. [CrossRef]

47. Ming, G.L.; Song, H. DISC1 partners with GSK3beta in neurogenesis. Cell 2009, 136, 990-992. [CrossRef]

48. Kitagishi, Y.; Kobayashi, M.; Kikuta, K.; Matsuda, S. Roles of PI3K/AKT/GSK3/mTOR Pathway in Cell Signaling of Mental Illnesses. Depress. Res. Treat. 2012, 2012. [CrossRef]

49. Manchia, M.; Rybakowski, J.K.; Sani, G.; Kessing, L.V.; Murru, A.; Alda, M.; Tondo, L. Lithium and bipolar depression. Bipolar Disord. 2019, 21, 458-459. [CrossRef] 
50. Cussotto, S.; Cryan, J.F.; O'Leary, O.F. The hippocampus and dorsal raphe nucleus are key brain areas associated with the antidepressant effects of lithium augmentation of desipramine. Neurosci. Lett. 2017, 648, 14-20. [CrossRef]

51. Planchez, B.; Surget, A.; Belzung, C. Adult hippocampal neurogenesis and antidepressants effects. Curr. Opin. Pharmacol. 2019, 50, 17-24. [CrossRef] [PubMed]

52. Wohleb, E.S.; Terwilliger, R.; Duman, C.H.; Duman, R.S. Stress-Induced Neuronal Colony Stimulating Factor 1 Provokes Microglia-Mediated Neuronal Remodeling and Depressive-like Behavior. Biol. Psychiatry 2018, 83, 38-49. [CrossRef] [PubMed]

53. Wang, Y.L.; Han, Q.Q.; Gong, W.Q.; Pan, D.H.; Wang, L.Z.; Hu, W.; Yang, M.; Li, B.; Yu, J.; Liu, Q. Microglial activation mediates chronic mild stress-induced depressive- and anxiety-like behavior in adult rats. J. Neuroinflamm. 2018, 15, 21. [CrossRef] [PubMed]

54. Alcocer-Gomez, E.; Ulecia-Moron, C.; Marin-Aguilar, F.; Rybkina, T.; Casas-Barquero, N.; Ruiz-Cabello, J.; Ryffel, B.; Apetoh, L.; Ghiringhelli, F.; Bullon, P.; et al. Stress-Induced Depressive Behaviors Require a Functional NLRP3 Inflammasome. Mol. Neurobiol. 2016, 53, 4874-4882. [CrossRef]

55. Feng, X.; Zhao, Y.; Yang, T.; Song, M.; Wang, C.; Yao, Y.; Fan, H. Glucocorticoid-Driven NLRP3 Inflammasome Activation in Hippocampal Microglia Mediates Chronic Stress-Induced Depressive-Like Behaviors. Front. Mol. Neurosci. 2019, 12, 210. [CrossRef]

56. Alcocer-Gomez, E.; de Miguel, M.; Casas-Barquero, N.; Nunez-Vasco, J.; Sanchez-Alcazar, J.A.; Fernandez-Rodriguez, A.; Cordero, M.D. NLRP3 inflammasome is activated in mononuclear blood cells from patients with major depressive disorder. Brain Behav. Immun. 2014, 36, 111-117. [CrossRef]

57. Ashraf, A.; Mahmoud, P.A.; Reda, H.; Mansour, S.; Helal, M.H.; Michel, H.E.; Nasr, M. Silymarin and silymarin nanoparticles guard against chronic unpredictable mild stress induced depressive-like behavior in mice: Involvement of neurogenesis and NLRP3 inflammasome. J. Psychopharmacol. 2019, 33, 615-631. [CrossRef]

58. Yue, N.; Huang, H.; Zhu, X.; Han, Q.; Wang, Y.; Li, B.; Liu, Q.; Wu, G.; Zhang, Y.; Yu, J. Activation of P2X7 receptor and NLRP3 inflammasome assembly in hippocampal glial cells mediates chronic stress-induced depressive-like behaviors. J. Neuroinflamm. 2017, 14, 102. [CrossRef]

59. Yi, J.H.; Brown, C.; Whitehead, G.; Piers, T.; Lee, Y.S.; Perez, C.M.; Regan, P.; Whitcomb, D.J.; Cho, K. Glucocorticoids activate a synapse weakening pathway culminating in tau phosphorylation in the hippocampus. Pharmacol. Res. 2017, 121, 42-51. [CrossRef]

60. Wiegert, O.; Pu, Z.; Shor, S.; Joels, M.; Krugers, H. Glucocorticoid receptor activation selectively hampers $\mathrm{N}$-methyl-D-aspartate receptor dependent hippocampal synaptic plasticity in vitro. Neuroscience 2005, 135, 403-411. [CrossRef]

61. Li, Z.; Sheng, M. Caspases in synaptic plasticity. Mol. Brain 2012, 5, 15. [CrossRef]

62. Yang, C.H.; Huang, C.C.; Hsu, K.S. Behavioral stress modifies hippocampal synaptic plasticity through corticosterone-induced sustained extracellular signal-regulated kinase/mitogen-activated protein kinase activation. J. Neurosci. 2004, 24, 11029-11034. [CrossRef] [PubMed]

63. Kim, J.J.; Foy, M.R.; Thompson, R.F. Behavioral stress modifies hippocampal plasticity through N-methyl-D-aspartate receptor activation. Proc. Natl. Acad. Sci. USA 1996, 93, 4750-4753. [CrossRef] [PubMed]

64. Furay, A.R.; Bruestle, A.E.; Herman, J.P. The role of the forebrain glucocorticoid receptor in acute and chronic stress. Endocrinology 2008, 149, 5482-5490. [CrossRef] [PubMed]

65. Zunszain, P.A.; Anacker, C.; Cattaneo, A.; Carvalho, L.A.; Pariante, C.M. Glucocorticoids, cytokines and brain abnormalities in depression. Prog. Neuropsychopharmacol. Biol. Psychiatry 2011, 35, 722-729. [CrossRef] [PubMed]

66. Freitas, A.E.; Egea, J.; Buendia, I.; Navarro, E.; Rada, P.; Cuadrado, A.; Rodrigues, A.L.; Lopez, M.G. Agmatine induces Nrf2 and protects against corticosterone effects in hippocampal neuronal cell line. Mol. Neurobiol. 2015, 51, 1504-1519. [CrossRef] [PubMed]

67. Kim, W.Y.; Wang, X.; Wu, Y.; Doble, B.W.; Patel, S.; Woodgett, J.R.; Snider, W.D. GSK-3 is a master regulator of neural progenitor homeostasis. Nat. Neurosci. 2009, 12, 1390-1397. [CrossRef]

68. Bradley, C.A.; Peineau, S.; Taghibiglou, C.; Nicolas, C.S.; Whitcomb, D.J.; Bortolotto, Z.A.; Kaang, B.K.; Cho, K.; Wang, Y.T.; Collingridge, G.L. A pivotal role of GSK-3 in synaptic plasticity. Front. Mol. Neurosci. 2012, 5, 13. [CrossRef] 
69. Green, H.F.; Nolan, Y.M. GSK-3 mediates the release of IL-1beta, TNF-alpha and IL-10 from cortical glia. Neurochem. Int. 2012, 61, 666-671. [CrossRef]

70. Paxinos, G.; Franklin, K.B.J. The Mouse Brain in Stereotaxic Coordinate; Gulf Professional Publishing: Houston, TX, USA, 2004.

(C) 2020 by the authors. Licensee MDPI, Basel, Switzerland. This article is an open access article distributed under the terms and conditions of the Creative Commons Attribution (CC BY) license (http://creativecommons.org/licenses/by/4.0/). 